\title{
PENGARUH LATIHAN SMALL SIDE GAMES TERHADAP KELINCAHAN PADA PERMAINAN SEPAKBOLA
}

\author{
Yovinianus Mbede Wea ${ }^{1}$ \\ ${ }^{1}$ Program Studi Pendidikan Jasmani Kesehatan dan Rekreasi, STKIP Citra Bakti Ngada, \\ Indonesia \\ e-mail: $\underline{\text { YovinianusMW@gmail.com }}$
}

\begin{abstract}
Abstrak
Tujuan penelitian ini adalah untuk mengetahui pengaruh latihan Small Side Games (2VS2, 3VS3, 4VS4) terhadap kelincahan dalam permainan sepak bola pada kegiatan ekstrakurikuler siswa di SMAK Thomas Aquino. Penelitian ini menggunakan rancangan non equivalent pre test - post test control gruop design. Sampel penelitian sebanyak 30 orang yang kemudian dikategorikan kedalam 2 kelompok yaitu kelompok kontrol dan kelompok eksperimen dengan masing-masing berjumlah 15 orang dengan teknik intac group. Data dikumpulkan dengan tes tindakan, kemudian dianalisis gain score ternormalisasi dengan teknik t-tes. Berdasarkan hasil uji hipotesis, bahwa ada pengaruh yang signifikan pada kelompok eksperimen, yaitu dengan latihan Small Side Games. Berdasarkan rata-rata hitung ditemukan bahwa kelompok eksperimen lebih besar dari kelompok control $\left(\ddot{\mathrm{x}}_{1}=0.0250>\ddot{\mathrm{x}}_{2}=0.0196\right)$. Selain itu, dari hasil analisis uji $\mathrm{t}$ di atas diperoleh nilai t-hitung sebesar 5.1910 dan t-tabel pada taraf signikansi $\alpha=0,05$ adalah 2.048. Karena t-tabel 2.048 lebih kecil dari t-hitung 5.1910, maka H0 ditolak dan H1 diterima. Kesimpulanya bahwa latihan small side games berpengaruh terhadap kelincahan pada permainan sepakbola.
\end{abstract}

Kata-kata kunci : small side games, kelincahan, sepakbola

\begin{abstract}
The purpose of this research is to know the exercise influence of small side games (2 VS 2, 3 VS 3, 4 VS 4) against agility in the football game on the students extracurricular activities at SMAK Thomas Aquino. The research uses the non equivalent pre test - post test control gruop design. This research was conducted with a total of 30 samples which were categorized into 2 groups: 1 control group and 1 more experimental group with 15 persons each with INTAC group technique. The data is collected with action tests, then the accumulated data is analyzed for the normalized score with the T-Test technique. Based on the hypothesis test results, there is a very significant influence on the group of experiments or treatment groups, namely by training Small Side Games. Based on average count it was found that the experiment group was larger than the control group $\left(\ddot{x}_{1}=0.0250>\ddot{x}_{2}=0.0196\right)$. In addition, from the results of T-Test analysis above obtained T-Calculate value of 5.1910 and T-table of a signikansi $\alpha=0.05$ is 2,048. Since the T-table 2,048 is smaller than the T-Count 5.1910, then HO is rejected and H1 is accepted. The conclusion that small side games exercise effects the agility of football.
\end{abstract}

Keywords: small side games, agility, football 


\section{PENDAHULUAN}

Kualitas proses pembelajaran penjasorkes akan dibedakan pada kegiatan pembelajaran dan kegiatan ekstrakurikuler semakin baik kualitas pembelajaran yang diterapkan guru, maka akan memberikan dampak positif terhadap kemampuan dan keterampilan siswa pada materi ajar yang diberikan. Dalam hal ini maka seorang tenaga pendidik harus bisa membedakan antara kegiatan pembelajaran dan latihan. Sepakbola merupakan cabang olahraga yang populer dan digemari oleh masyarakat Indonesia pada saat ini, hal ini bisa dilihat dari antusiasme masyarakat Indonesia terhadap olahraga ini, mulai dari anak-anak sampai orang dewasa semua begitu antusias ketika membahas tentang sepakbola. Permainan sepakbola dapat dikatakan sebagai olahraga permainan yang sangat menarik dan dapat dimainkan oleh semua golongan umur, karena pada dasarnya permainan ini diciptakan dengan konsep sebuah permainan yang dimainkan dengan menonjolkan unsur kesenangan dan dimainkan secara beregu. Seiring dengan perkembangan zaman, maka bertambah pula fungsi dan manfaat sepakbola, selain untuk olahraga prestasi dan olahraga ini bisa dijadikan sebagai sarana hiburan.

Pembelajaran di suatu lingkungan pendidikan tidak lepas dari prestasi olahraga dengan melalui kegiatan ekstrakurikuler, kegiatan ini salah satu bentuk dalam pengolahan diri peserta didik dalam mengembangkan bakat dan minat yang bertujuan ke arah prestasi. Kegiatan ekstrakurikuler yang paling digemari salah satunya sepakbola. Kegiatan ekstrakurikuler merupakan kegiatan pengembangan diri peserta didik pada kegiatan luar sekolah. Mengingat banyaknya peminat olahraga sepakbola, maka olahraga ini menjadi kegiatan ekstrakurikuler unggulan. Untuk itu kegiatan kegiatan tersebut harus terprogram dengan baik dan benar agar peserta didik dapat melakukan kemampuan secara maksimal dengan baik dan benar.

Berdasarkan pengamatan serta wawancara kepada pelatih tim sepak bola SMAK Thomas Aquino bahwa terjadi penurunan prestasi di tingkat kecamatan dan kabupaten. Salah satu mepengaruhi adalah faktor kelincahan dalam melakukan perpindahan arah tanpa bola dan kecepatan merubah arah disaat berlari mengejar atau merebut bola. Selama latihan, pelatih cenderung memberikan pola latihan 11 vs 11 atau biasa disebut permainan murni (monoton) tanpa ada latihan yang termodifikasi. Untuk itu diperlukan modifikasi pola pelatihan fisik selain agar peserta didik meningkat kemampuannya juga tidak mengalami kebosanan. Hal ini senada yang disampaikan Nursaelan pelatih fisik Timnas U-19 Indonesia bahwa apapun gaya bermain seseorang ataupun pada tim untuk memenangkan suatu pertandingan tidak terlepas dari yang namanya latihan dengan intensitas yang baik juga seorang atlet harus memiliki inovasi dan kreatifitas dalam melakukan latihan yang berdampak pada komponen biomotorik (fisik seseorang) termasuk salah satu komponen biomotorikinya. Melihat permasalahan ini peneliti mencoba menerapkan bentuk pelatihan yang sederhana tetapi tujuan untuk meningkatkan kelincahan yaitu melalui latihan small side game. Metode latihan small side game, dapat membantu siswa untuk bergerak dengan lincah, dari penyergapan lawan ( Morgan, 1984)

Small side games adalah suatu bentuk latihan bermain yang dilakukan dengan berbagai pembatas, pembatas tersebut meliputi luas lapangan, jumlah pemain, lamanya latihan dan syarat 
atau peraturan. Small side game bermanfaat untuk mengidentifikasi bakat seorang pemain sepak bola, latihan small side game sering digunakan orang dewasa sebagai bagian dari program pelatihan yang reguler dalam berbagai format, tergantung pada tujuan dan filosofi pelatih. Peningkatan dan pengembangan kondisi fisik dilakukan dengan skala proritas sesuai dengan kebutuhan (Nala, 2011). Ditambahkan Rampinini et al. (2007), yang perlu digaris bawahi pentingnya penggunaan latihan small side game sangatlah berbeda karena bentuk latihannya mengubah setiap kali banyaknya peserta dari suatu bentuk game dengan suatu yang lebih besar. Dalam latihan small side game, masingmasing pemain berhubungan dengan bola dan hadapi dengan situasi game yang umum (Capranica et al. 2001). Situasi ini memerlukan kecakapan teknis baik seperti, menggiring dan menendang, serta taktis keterampilan seperti lari tanpa bola dan kerjasama dengan pemain lain.

Metode latihan small side game dapat mempengaruhi otot- otot tungkai bawah seperti, fibularis, soleus muscle, tendon, superior fibular, inferior fibelar, extensor halluces longus. Kekuatan otot tungkai bawah merupakan kekuatan otot untuk memberikan daya dorong yang kuat dan bertenaga pada saat orang beraktivitas khususnya saat berolahraga (Suharno HP, 1985). Otot - otot ini yang akan mempengaruhi kelincahan yang berfungsi untuk seorang atlet yang dilatih untuk meningkatkan kemampuan suatu aktifitas olahraga.

Kelincahan adalah kemampuan untuk mengubah arah dan posisi tubuh dengan cepat dan tepat pada waktu sedang bergerak, tanpa kehilangan keseimbangan dan kesadaran akan posisi tubuhnya (Muhajir, 2007).
Kelincahan sangat dibutuhkan hampir di setiap cabang olahraga. Menurut Ismaryati (2006: 41), kelincahan adalah kemampuan untuk mengubah arah dan posisi tubuh atau bagian-bagiannya secara cepat dan tepat. Selain dikerjakan dengan cepat dan tepat, perubahanperubahan tadi harus dikerjakan dengan tanpa kehilangan keseimbangan. Kelincahan merupakan salah satu unsur kondisi fisik yang berperan penting terutama pada cabang olahraga permainan termasuk sepakbola khususnya pada saat mendapat rintangan dari lawan.

Untuk meningkatkan kelincahan diperlukan latihan. Latihan adalah sebagai kegiatan yang dilakukan dalam jangka waktu lama, sistematik dan progresif sesuai dengan tingkat kemampuan individu, dengan tujuan untuk membentuk fungsi fisiologi dan psikologis yang memenuhi syarat untuk tugas-tugas kegiatan olahraga (Bompa, dalam Hadjarati, 2010: 38). Proses latihan dilakukan secara sistematis yaitu teratur, terencana, menggunakan pola dan system tertentu, metodis, berkesinambungan dari yang sederhana ke yang kompleks, dari yang mudah ke yang sukar.. Setiap gerak harus dilatih secara bertahap dan dikerjakan secara berkali-kali sehingga gerak menjadi efisien. Latihan merupakan faktor yang sangat penting dalam meningkatkan kemampuan fisik bagi pemain dengan kemampuan fisik yang dimiliki pemain dapat mempermudah melakukan gerakan teknik-teknik yang ada dalam permainan sepakbola dan mencegah terjadinya cedera sehingga dapat mencapai hasil maksimal, untuk itu perlu ditingkatkan kemampuannya melalui pelatihan yang benar. Small side games atau permainan di lapangan skala kecil merupakan situasi tepat yang dikembangkan untuk para pemain muda, supaya bisa belajar dan 
berkembang. Setiap permainan merupakan gabungan dari teknik khusus dalam sepakbola, misalnya menggiring, mengoper atau menembakkan bola, sertau berfokus pada kerjasama tim dan strategi, misalnya bertahan, menyerang, menciptakan ruang gerak, atau bergantian tugas. Melalui pelatihan small side game dapat memacu dan merangsang tolakan kaki agar kuat sehingga dapat meningkatkan kelincahan,

Berdasarkan latar belakang di atas maka peneliti tertarik untuk melakukan penelitan dengan judul "Pengaruh Latihan Small Side Games (2vs2, 3vs3, 4vs4) terhadap Kelincahan pada Permainan Sepakbola”.

\section{METODE}

Penelitian ini dilaksanakan di SMAK Thomas Aquino Golewa kabupaten Ngada. Pelaksanaan dari tanggal 24 Maret sampai 25 Mei 2019.Sedangkan post test dilaksanakan pada tanggal 25 Mei 2019. Waktu pretest dan post test dilaksanakan pada pukul 15.30 - 17.00 WITA pemberian perlakuan (treatment) dilksanakan sebanyak 12 kali pertemuan, dengan frekuensi 4 kali seminggu yaitu hari senin, rabu ,jumat dan sabtu dari pukul 15.00-17.00 WITA.

Metode yang digunakan dalam penelitian ini adalah quasi eksperimen dengan rancangan "Non Equivalent Pretest-Posttest Control Gruop Design" seperti pada gambar 1.

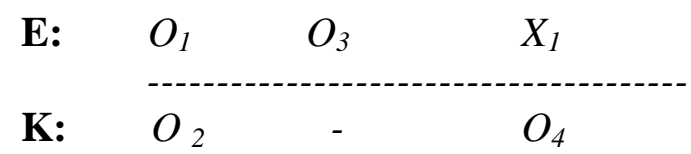

Gambar 1. Rancangan Penelitian

Keterangan :

$\mathrm{E}=$ Eksperimen
$\mathrm{K}=$ Kontrol

$\mathrm{X}_{1}=$ Perlakuan dengan latihan small side games

$\mathrm{O} 1=$ Pre-test kelompok Eksperimen

$\mathrm{O} 2=$ Pre-test kelompok Kontrol

O3= Post-test kelompok Eksperimen

O4= Post-test kelompok Kontrol.

Populasi dalam penelitian ini adalah adalah peserta didik SMAK Thomas Aquino. Sampel dalam penelitian ini adalah peserta didik SMAK Thomas Aquino yang memilih ekstrakurikuler sepakbola. Teknik pengambilan sampel dalam penelitian ini menggunakan teknik intac group. Pengambilan sampel dilakukan terhadap kelompok secara utuh, karena jika diacak secara individual, maka kelas itu akan berubah, sehingga hal ini tidak mungkin dilakukan. Jumlah sampel penelitian adalah 30 orang yang terdiri dari laki- laki sebanyak 15 orang dan perempuan 15 orang.

Instrumen yang digunakan untuk mengumpulkan data mengenai kelincahan adalah dengan tes lari bolakbalik (shutlle run). Pengukuran data Prosedur pelaksanaan tes lari bolakbalik adalah sebagai berikut.

1) Pada aba-aba "bersedia" testee berdiri di belakang garis tengah menghadap garis pertama,

2) pada aba-aba "siap" atlet lari dengan start berdiri,

3) Dengan aba-aba "ya" atlet segera berlari menuju ke garis pertama dan setelah kedua kaki melewati garis pertama segera berbalik dan menuju ke garis tengah

4) Atlet berlari lagi dari garis tengah menuju garis kedua dan kembali ke garis tengah, dihitung satu kali,

5) Pelaksanaan lari dilakukan sampai empat kali bolak-balik sehingga menempuh jarak 40 meter,

6) Setelah melewati finis di garis tengah, pencatat waktu dihentikan, 
7) Catatan waktu untuk menentukan norma kelincahan dihitung sampai persepuluh detik $(0,1$ detik $)$ atau perseratus detik $(0,01$ detik)

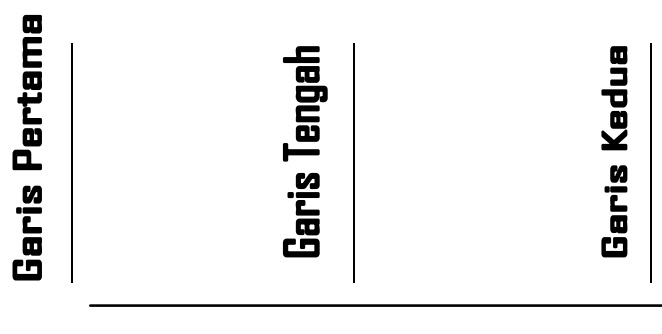

10 meter

Gambar 2. Lintasan Tes Lari BolakBalik

\section{HASIL DAN PEMBAHASAN}

Berdasarkan hasil analisis data menggunakan uji statistik dengan uji $t$ menunjukkan bahwa nilai t-hitung 5,1910 dan t-tabel pada taraf signifikansi 0,05 adalah 2,048. Sehingga t-hitung 5,1910 > dari 2,048 ttabel, maka H0 ditolak dan H1 diterima yang artinya model latihan small side games berpengaruh terhadap kelincahan pada permainan sepakbola. Pemberian perlakuan latihan small side games selama 12 kali pertemuan memberikan pengaruh terhadap kelincahan menggiring peserta ekstrakurikuler sepakbola di SMAK Thomas Aquino Mataloko. Hal ini didukung oleh pernyataan Putera (dalam Komarudin, 2013) yaitu latihan small side games dapat digunakan dalam proses latihan peningkatan daya tahan aerobik dalam permainan sepakbola karena dalam latihan ini mencakup aspek teknik, taktik dan fisik. Secara umum model latihan small side games dapat meningkatkan komponen fisik pemain sepakbola salah satunya adalah kelincahan. Senada dengan itu penelitian mengenai model latihan small side games juga pernah dilakukan oleh Irfan (2016) yang menemukan bahwa latihan small side games berpengaruh terhadap kelincahan pada pemain sepakbola di School Soccer Putra Zodiac dimana terdapat perbedaan sebelum dan sesudah diberikan latihan small side games dengan metode interval training. Deypaha (2016) juga menemukan bahwa terdapat pengaruh latihan small side games 4 vs 4 terhadap kelincahan pemain sepakbola SMA Negeri 2 Gorontalo.

Hasil penelitian diatas menunjukan terdapat perbedaan yang signifikan antara kelompok experimen dan kelompok kontrol. Hal ini disebabkan karena pemberian latihan sesuai dengan ketentuan "FITT" (frekuensi, intesitas, tipe dan time ) frekuensi, intesitas dan tipe dalam pelatihan ini sudah memenuhi ketentuan yaitu frekuensi 4 kali dalam seminggu, intesitas $85 \%$ dari denyut nadi maksimal dan tipe ( pelatihan bola, kun, dan pluit sebagai media ) untuk kelompook experimen latihan sesuai dengan aturan dan bimbingan oleh peneliti, sedangkn kelompok kontrol latihan sesuai dengan kebiasaan sampel.

\section{SIMPULAN DAN SARAN \\ Hasil}

Dari hasil analisis disimpulakan bahwa:

1. Latihan small side games (2VS2, $3 V S$ 3, 4VS4) berpengaruh positif terhadap kelincahan sepak bola siswa SMAK Thomas Aquini Golewa Tahun Ajaran 2018/2019,

2. Ada perbedaan pengaruh yang signifikan antara keolompok eksperimen dan kelompok kontrol. Dimana kelompok eksperimen (latihan small side games) memberikan pengaruh yang lebih baik dibandingan dengan kelompok kontrol. 


\section{Saran}

Berdasarkan bukti dari hasil penelitian, dengan variabel latihan small side games (2 VS 2, 3VS 3, 4 VS 4) yang memberi pengaruh terhadap kelincahan sepak bola bola maka disarankan beberapa hal sebagai berikut.

1. Untuk pelatih, pembina serta guru olahraga dan masyarakat pada umumnya yang ingin meningkatkan kelincahan sepakbola dapat dilakukan dengan latihan Small Side Games (2 VS 2, 3VS 3, 4 VS 4).

2. Bagi para peneliti diharapkan hasil penelitian ini dapat dijadikan pedoman atau acuan dalam melakukan penelitian selanjutnya dangan menambah frekuensi dan intensitas latihan.

\section{DAFTAR PUSTAKA}

Charaka R.W, Dkk: 2018. Pengaruh Latihan Small-Sided Games Terhadap Keterampilan Passing, Controlling dan Shooting Peserta Ekstrakurikuler Sepakbola SMK Negeri 1 Tegalsari Kabupaten Banyuwangi. Jurnal Kejaora, Volume 3 Nomor 2, Hal. 194-201. Universitas PGRI Banyuwangi.

Capranica, L., Tessitore, A., Guidetti, L. and Figura, F. (2001) Heart rate and match analysis in prepubescent soccer players. Journal of Sports Sciences 19, 379-384

Deypaha, I. (2016). Pengaruh Latihan Small Sided Games Terhadap Peningkatan Daya Tahan Cardiovascular dan Kelincahan Pada Pemain Sepak Bola SMA Negeri 2 Gorontalo. Skripsi, 1(832410075).
Hadjarati, 2010. Pendidikan Jasmani Teori dan Praktek. Jakarta: Erlangga.

Harsono, 2010. Ilmu Kepelatihan Olaharaga STO. Yogyakarta.

Irfan, A. (2016). Pengaruh Latihan Small Sided Games Dengan Metode Interval Training Terhadap Peningkatan Kelincahan Pada Pemain Sepakbola Di School Soccer Putra Zodiac Usia 15-16 Tahun. Jurnal Kesehatan Olahraga, 4(2).

Ismaryati. (2006). Tes dan pengukuran olahraga. UNS Press, Surakarta.

Koyan, I Wayan. M.Pd. 2007. Statistic Pendidikan. Teknik Analisis Data Kuantitatif. Bali : Universitas Pendidikan Ganesha Press.

Morgan. 1984. Theory and Methodology Training :to Key to Athletic Performance. Canada: Kendall/Hunt Publisher Company.

Muhajir. 2007 (2007). Pendidikan Jasmani Teori dan Praktek. Jakarta: Erlangga

Nala, 2011. Prinsip Pelatihan Fisik Olahraga. Universitas Udayana Denpasar

Rampinini, E., Impellizzeri, F., Castagna, D., Abt, G.A., Chamari, K.Sassi, A. and Marcora, M. (2007). Factors influencing physiological responses to smallsided soccer games. Journal of Sports Sciences 25, 659-666.

Riduwan, Nazir dan Akdon. 2013. Rumus dan Data dalam Aplikasi Statistik. Bandung: Alfabeta

Suharno.HP. (1985). Ilmu kepelatihan olah raga yayasan STO. Yogyakarta. 
JURNAL PENJAKORA

Volume 7 No 1, Edisi April 2020 